Research Journal of Applied Sciences 13 (12): 725-728, 2018

ISSN: $1815-932 \mathrm{X}$

(C) Medwell Journals, 2018

\title{
The Extreme Currency Exchange Rate in South East Asia Using Classical and Bayesian Methods
}

\author{
${ }^{1}$ Arisman Adnan, ${ }^{2}$ Rado Yendra, ${ }^{2}$ Muhammad Marizal and ${ }^{3}$ Ahmad Fudholi \\ ${ }^{1}$ Department of Mathematics FMIPA, Universitas Riau, Pekanbaru, Riau, Indonesia \\ ${ }^{2}$ Department of Mathematics, Faculty of Science and Technology, \\ Universitas Islam Negeri Sultan Syarif Kasim (UIN Suska), 28293 Pekanbaru, Riau, Indonesia \\ ${ }^{3}$ Solar Energy Research Institute, Universiti Kebangsaan Malaysia, \\ 43600 Bangi, Selangor, Malaysia
}

\begin{abstract}
The exchange rates of four currencies in South Asia depend on the Foreign exchange market among those countries. In most cases, the best fitting distribution of exchange rates are found to follow the generalized logistic distribution. Now, we seek for the best distribution to describe the extreme daily exchange rate from 1993-2013 for 4 countries in Southeast Asia using the classical and Bayesian methods. We use the maximum likelihood method for classical approach while Generalized Extreme Value (GEV) distribution and generalized logistic distribution for Bayesian approach. The estimate of the three-parameters of extreme values distribution have been compared using goodness-of-fit test. The tests show us that there is no significant difference of parameter estimated between these two distributions. Furthermore, the best distribution for fitting the model of these exchange rates is GEV.
\end{abstract}

Key words: Extreme values, currency exchange rate, classical method, Bayesian method, three-parameters, distribution, classical approach

\section{INTRODUCTION}

Over the past few decades, the movement of the exchange rate has become an important subject of macro-economic analysis. However, despite many attempts to build models and forecasting currency exchange rates, it is still a challenge for academics and market practitioners. Sample forecast in the currency exchange is always predict well but in reality is often disappointing because it is different from the reality that actually happened. Not withstanding this, many researchers have devoted their researches about a model that can predict the conditions in the future such as (Chong et al., 2002) used the model of the BMA, Canova (1993) used Bayesian Time-Varying Coefficients (TVC), Liu and Mahieu (2010) used Bayesian forecasting methods Model Winner (BMW) and Bayesian Model Average used Possible divination (BMAP). Therefore, it is necessary to make a model in the form of extreme distribution to process extremes currency exchange data that can help research to predict the random movements of currency exchange. Oyinlola studied the short-run and long run impact of real exchange rate depreciation on trade balance in Nigeria using data from 1980-2007 and three different approaches to test for counteraction. Umar examined the Holt-Winter, double exponential and the linear regression trend parameter estimation techniques and compare their forecast quality via. the criteria of forecast as in Gilchrist.

In this study, analysis of extreme value is conducted using currency exchange data over the daily maximum of 20 years in four countries of Southeast Asia Region. This analysis involves the distribution of Extreme Value (GEV) and Distribution Logistics (GLD). Parameter estimation is determined using classical methods (maximum likelihood) and Bayesian methods. Previous research has also been conducted by Akbarizan et al. (2016), using L-momem and maximum likelihood. The comparison is made to determine the most appropriate distribution to describe the extreme data for each country using the test model accuracy. Simulation and data processing is done using the programming language $\mathrm{R}$.

In the next section, we disclose data that used together with descriptive statistics involving average, standard deviation and coefficient of variation for annual extreme daily currency exchange. Next, we describe the method of parameter estimation and model accuracy test process. The results of the analysis are discussed in the next study and the last part discusses the overall findings and conclusions.

Corresponding Author: Arisman Adnan, Department of Mathematics FMIPA, Universitas Riau, Pekanbaru, Riau, Indonesia 


\section{MATERIALS AND METHODS}

In this study, the currency exchange rate is the object of the statistical distribution adjustment studied. Data taken in this study is the type of data exchange mid Malaysian Ringgit against the Singapore Dollar (SGD), Indonesian Rupiah (IDR), the Thai Baht (THB) and the Philippine Peso (PHP). The interval is daily data from September 1993-February 2013. Data were obtained from sites www.oanda.com/currency/historical-rates/. In this site there are three types of currency exchange data, aks, bid and mid. Aks is the type of data based on supply. Bid is data on demand. Furthermore, mid is the type of data that was taken the mean value of demand and supply. The currency exchange rate movements of all four countries over a 20 year period can be seen in Fig. 1.
The probability density function and quantile function for any distribution can be seen in Table 1 where $\mathrm{y}$ is a sample of a random variable, $\alpha$ represents the scale parameter, $\mu$ is the location parameter and $\mathrm{k}$ represents the shape parameter. When we have the model from this data, then, we will get the classic method of parameter estimation with maximum likelihood and Bayesian methods. In the maximum likelihood method, to obtain the estimation of the parameters $\mu, \alpha$ and $\mathrm{k}$, nonlinear partial equations $\partial 1 / \partial \mu=0, \partial 1 / \partial \alpha=0$ and $\partial 1 / \partial \mathrm{k}=0$ must be completed. This settlement can only be done by numerical methods. The method often used to estimate the distribution that has three parameters is Newton-Rhapson method. Meanwhile, Bayesian parameter estimation method is using no prior declaration. Prior is scouted with assumption that no declaration is related to the data acquisition process (Table 1).

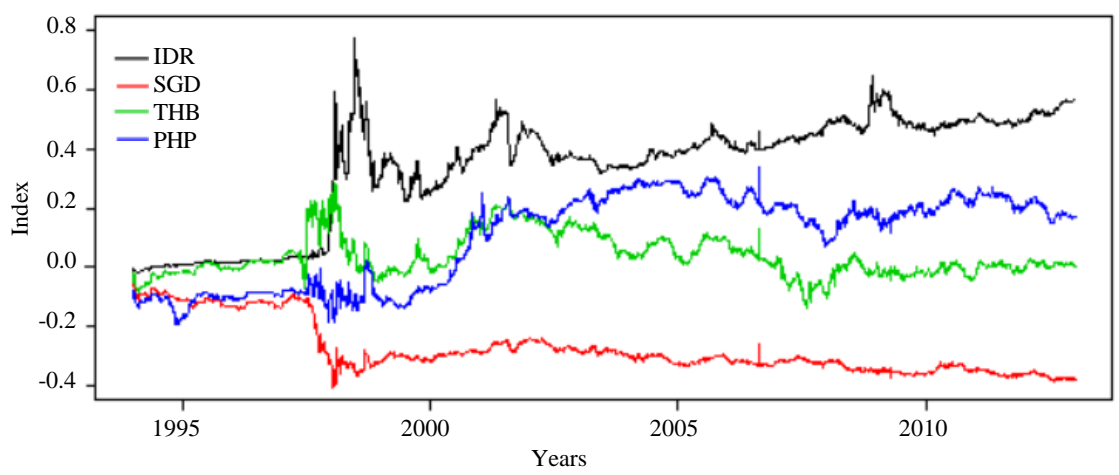

Fig. 1: Daily currency exchange index

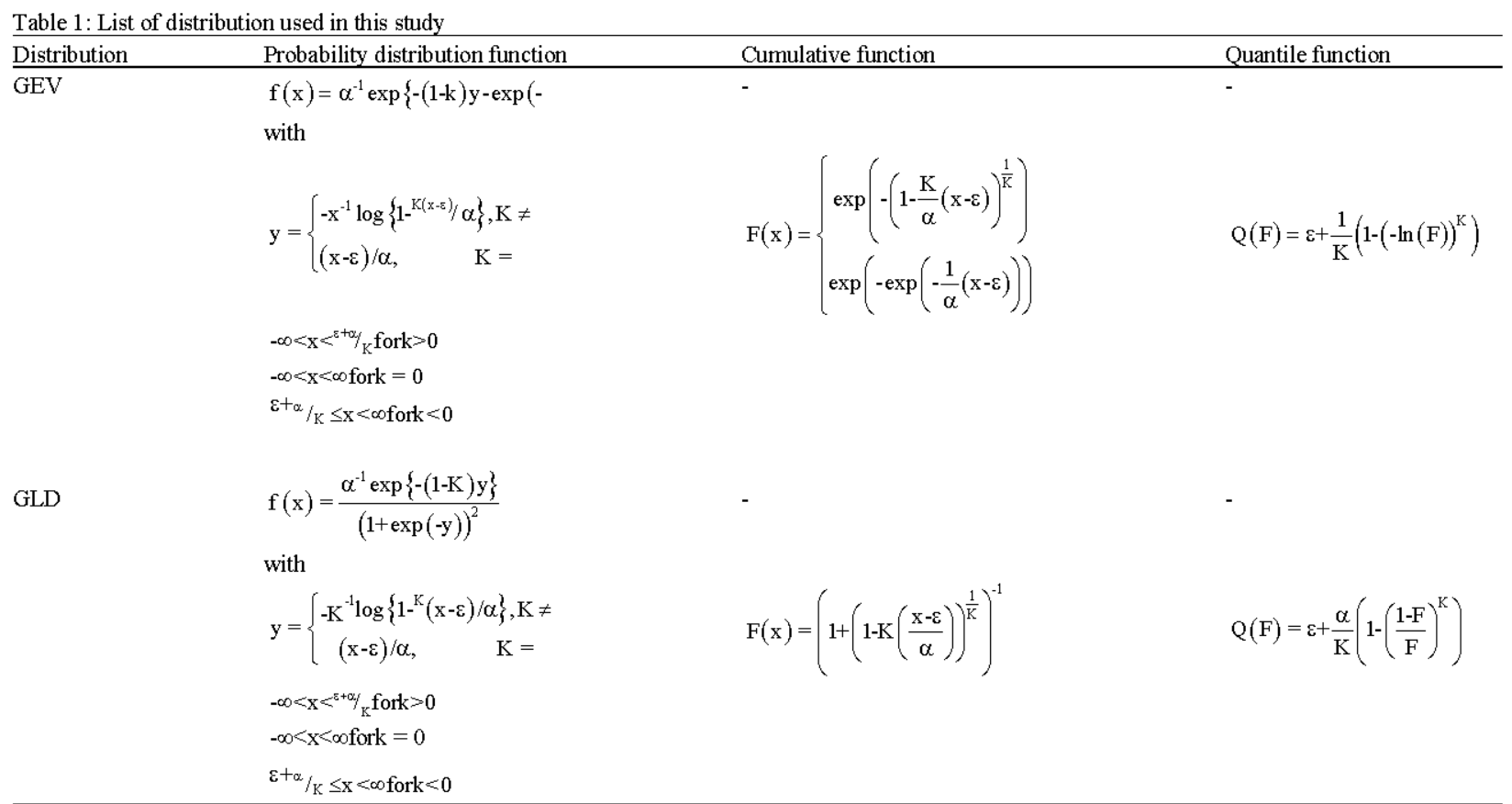




\section{RESULTS AND DISCUSSION}

Table 2 shows the results of the estimation adaptive parameter values $\mu, \alpha$ and $\kappa$ obtained from the maximum likelihood method and Bayesian method. Acquisition parameters by Bayesian method has been carried repetition 40000 where the first 10000 algorithms had been discarded. Meanwhile, test the accuracy of the model (GOF) of each method are shown in Table 3. As a simulated picture of Bayesian methods, Fig. 2 displays one simulation for data exchange, namely the Singapore dollar. The comparison between the Bayesian method

Table 2: The values of parameters obtained from the classical and Bayesian methods

\begin{tabular}{|c|c|c|c|c|c|c|}
\hline \multirow[b]{2}{*}{ Country } & \multicolumn{2}{|c|}{ Distribution } & \multicolumn{2}{|c|}{ Maximum likelihood } & \multicolumn{2}{|l|}{ Bayesian } \\
\hline & $(\hat{\mu})$ & $(\hat{\alpha})$ & $(\hat{\mu})$ & $(\hat{\mathrm{k}})$ & $(\hat{\alpha})$ & $(\hat{\mathrm{k}})$ \\
\hline \multicolumn{7}{|l|}{ SGD } \\
\hline GEV & 0.44988 & 0.037440 & -0.31200 & 0.454560 & 0.042460 & -0.299670 \\
\hline GLD & 0.46417 & 0.030400 & -0.47247 & 0.464900 & 0.032390 & -0.449200 \\
\hline \multicolumn{7}{|l|}{ IDR } \\
\hline GEV & 2273.628 & 994.6631 & 0.79430 & 2348.868 & 994.1051 & 0.749348 \\
\hline GLD & 2593.052 & 475.9249 & 0.44433 & 2651.317 & 452.0926 & 0.447903 \\
\hline \multicolumn{7}{|l|}{ THB } \\
\hline GEV & 10.34374 & 0.498320 & -0.40780 & 10.35135 & 0.550000 & -0.301120 \\
\hline GLD & 10.5428 & 0.438650 & -0.55828 & 10.50601 & 0.451700 & -0.451460 \\
\hline \multicolumn{7}{|l|}{ PHP } \\
\hline GEV & 13.12663 & 1.877010 & 0.83748 & 13.09671 & 1.898270 & 0.654610 \\
\hline GLD & 13.82899 & 0.844200 & 0.49642 & 0.700690 & 0.900520 & 0.450010 \\
\hline
\end{tabular}

Table 3: Value Test the accuracy of the model derived from classical methods and Bayesian methods

\begin{tabular}{|c|c|c|c|c|c|c|}
\hline \multirow[b]{2}{*}{ Country } & \multicolumn{2}{|l|}{ Distribution } & \multicolumn{2}{|c|}{ Maximum likelihood } & \multicolumn{2}{|l|}{ Bayesian } \\
\hline & RRMSE & RASE & PPCC & RRMSE & RASE & PPCC \\
\hline \multicolumn{7}{|l|}{ SGD } \\
\hline GEV & 0.2534776 & 0.1865732 & 1.0000000 & 0.2739865 & 0.1991058 & 1.0000000 \\
\hline GLD & 0.2756091 & 0.1957962 & 0.9999999 & 0.2807084 & 0.2003838 & 1.0000000 \\
\hline \multicolumn{7}{|l|}{ IDR } \\
\hline GEV & 0.2841819 & 0.1780645 & 0.9866420 & 0.2811221 & 0.1924809 & 0.9868201 \\
\hline GLD & 0.6853220 & 0.2858733 & 0.9658340 & 0.6287724 & 0.2794066 & 0.9702682 \\
\hline \multicolumn{7}{|l|}{ ТНB } \\
\hline GEV & 0.1445324 & 0.1071660 & 0.9999991 & 0.1367453 & 0.1043956 & 0.9999992 \\
\hline GLD & 0.1666608 & 0.1165484 & 0.9999987 & 0.1484652 & 0.1109174 & 0.9999990 \\
\hline \multicolumn{7}{|l|}{ PHP } \\
\hline GEV & 0.0894574 & 0.0717914 & 0.9999996 & 0.0892745 & 0.0748249 & 0.9999996 \\
\hline GLD & 0.1394943 & 0.0875837 & 0.9999988 & 0.1350220 & 0.0858253 & 0.9999990 \\
\hline
\end{tabular}

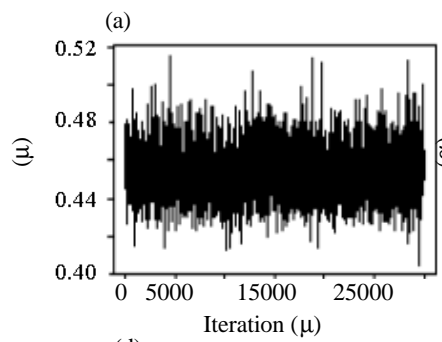

(b)

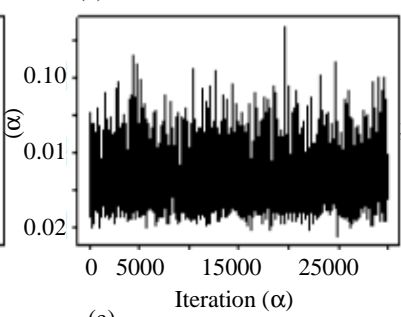

(e) $\operatorname{Iteration}(\alpha)$

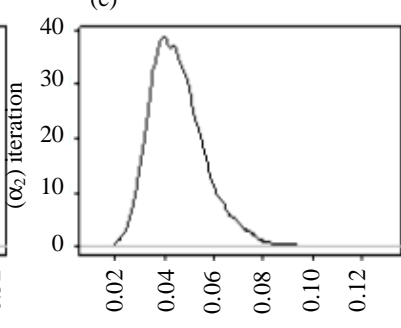

$(\alpha)$ (c)

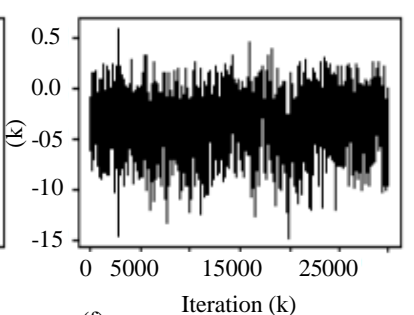

(f) Iteration (k)

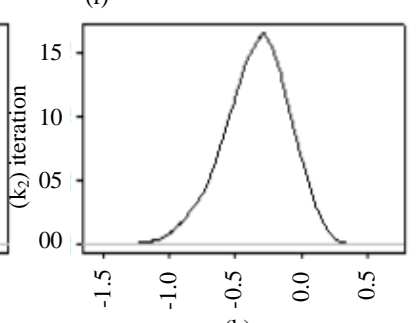

(k)

Fig. 2: Simulation of GEV distribution for Singapore dollar; a) Iteration $(\mu)$; b) Iteration $(\alpha)$; c) Iteration ( $(\kappa)$ 
with classical methods shows that the classic method of maximum likelihood method to estimate the parameters Bayesian fits with GEV distribution for extreme exchange rate in all the studied countries.

The same result is obtained in the study by Eli et al. (2012) that Bayesian method and maximum likelihood method are more appropriate to estimate parameters for the GEV distribution. In terms of model accuracy test (GOF), the Bayesian method and maximum likelihood method is not much different. Theoretically, parameter estimation using Bayesian methods with prior without declaration resemble the maximum likelihood method (Casella and Berger, 1990).

\section{CONCLUSION}

From the research that has been conducted shows that the best distribution for each of the countries examined in modeling extreme currency exchange rate is the GEV distribution. However, both methods are used to estimate the parameters are not much different based on the test the model accuracy. The conclusion of this study indicates that the classic method of maximum likelihood has no different with the Bayesian method with no prior. Therefore, to convince us that the principle of Bayesian might be better than the classical principle, we propose to further research using Bayesian priors to test the accuracy of the model that corresponds to Bayesian methods such as AIC.

\section{ACKNOWLEDGEMENT}

This research is fully supported by Riau Statistical Research Center, Indonesia.

\section{REFERENCES}

Akbarizan, A., M. Marizal, R.Y. Yendra, K. Kusaeri and A. Despina et al., 2016. Annual maximum exchange rate in Southeast Asia based on methods of Lmoment and maximum likelihood. Res. J. Appl. Sci. Eng. Technol., 13: 273-276.

Canova, F., 1993. Modelling and forecasting exchange rates with a Bayesian time-varying coefficient model. J. Econ. Dyn. Control, 17: 233-261.

Casella, G. and R.L. Berger, 1990. Statistical Inference. Duxbury Press, California, USA.,.

Chong, C.W., L.S. Chun and M.I. Ahmad, 2002. Modeling the volatility of currency exchange rate using GARCH model. Petranka J. Soc. Sci. Hum., 10: 85-95.

Eli, A., M. Shaffie and W.Z.W. Zin, 2012. Preliminary study on Bayesian extreme rainfall analysis: A case study of Alor Setar, Kedah, Malaysia. Sains Malaysiana, 41: 1403-1410.

Liu, Y. and R.J. Mahieu, 2010. Exchange rate predictability: Bayesian model selection. Master Thesis, Network for Studies on Pensions, Aging and Retirement, Tilburg University, Tilburg, Netherlands. 